\title{
Instituciones y Derecho Indiano en una renovada Historia de América/
}

\author{
Institutions and Derecho Indiano \\ in a Renewed History of America
}

Víctor Tau Anzoátegui

ORCID iD: https://orcid.org/0000-0001-7327-0472

CONICET/Instituto de Investigaciones de Historia del Derecho

Este ensayo historiográfico trata acerca de la construcción científica de la historia de la colonización española en América a través de las instituciones y del derecho indiano, que en la primera mitad del siglo XX promovieron principalmente Rafael Altamira y José M. Ots Capdequí. Una interesante proyección de esa tarea se puede observar inicialmente en los primeros números del Anuario de Estudios Americanos de Sevilla.

Palabras ClaVE: Americanismo; Historiografía; Instituciones; Derecho indiano.

This historiographical essay addresses the scientific construction of the history of Spanish colonization in America through the institutions and the Derecho Indiano, promoted mainly by Rafael Altamira and José M. Ots Capdequí in the first half of the 20th Century. An interesting projection of that work can be observed initially in the first issues of the Anuario de Estudios Americanos of Seville.

KEYwords: Americanism; Historiography; Institutions; Derecho indiano.

Copyright: (C) 2018 CSIC. Este es un artículo de acceso abierto distribuido bajo los términos de la licencia de uso y distribución Creative Commons Reconocimiento 4.0 Internacional (CC BY 4.0). 


\section{Preliminares}

Me siento muy honrado por la invitación a participar en este número conmemorativo de los setenta y cinco años de existencia del Anuario de Estudios Americanos. Con una trayectoria ininterrumpida desde su creación en 1944 ha alcanzado en este largo tiempo una circulación con reconocida acreditación científica en los ámbitos de estudio de Europa y América. En su amplitud y variedad abarca un conjunto de materias que alcanza a cubrir áreas altamente significativas de las ciencias sociales y humanidades.

Mi propósito en este breve ensayo es observar un aspecto de la relación que unió a este Anuario en sus comienzos con la etapa constitutiva de la Historia del Derecho Indiano como disciplina científica. En esos años actuaban tres principales figuras que, a mi juicio, marcaron rumbos certeros en la especialidad jurídica indiana, cada una en sus tiempos y modos: Rafael Altamira y Crevea (1866-1951), Ricardo Levene (1885-1959) y José María Ots Capdequí (1893-1975).

Ellos dieron impulso y configuración científica a una disciplina acuñada en el seno de la historiografía americanista y conducida en su etapa inicial por la fuerte personalidad del primero de ellos. En esas décadas iniciales del siglo XX, complejas y cambiantes, el modelo de la cátedra universitaria y el seminario histórico condujo a la formación de colecciones documentales y a la catalogación de registros y archivos de documentos históricos. Entre los repositorios, mereció una atención especial el Archivo General de Indias de Sevilla, emblema máximo del americanismo español, que experimentó ya en los tiempos de Altamira una transformación fundamental para colocarlo al servicio de los investigadores especializados. ${ }^{1}$ Hubo así un entronque visible entre esta nueva disciplina y la mayor fuente archivística del americanismo.

Las tres figuras mencionadas tuvieron, según se aprecia por los resultados logrados, una actuación directa en la preparación de la corriente de ideas que impregnaron, por sus temas y método, este americanismo en una perspectiva institucional y jurídica. No de otra manera se explica que el Anuario de Estudios Americanos actuara en los tiempos iniciales de su existencia como receptor de estudios y artículos propios de la historia institucional y de legislación indiana. Esto mismo nos lleva a ahondar en la

1 Vélez, 2007, 89-110. Peña y Cámara, 1958, 13-77. Calderón Quijano, 1987 (obra fundamental de conocimiento). 
personalidad y producción intelectual de estos tres historiadores, con la limitación que impone el espacio y con la restricción de ocuparnos solo de modo fugaz del campo de actuación de cada uno y desde el cual transmitieron sus enseñanzas y directivas en el terreno de la investigación.

También nos ocuparemos de algunas otras figuras de una generación posterior que marcaron con su sello propio el avance de estos estudios de las instituciones y el derecho indiano, y fueron discípulos personales o intelectuales de aquellos maestros. Entre ellos destacan los catedráticos de Sevilla: Juan Manzano Manzano (1911-2004) y Antonio Muro Orejón (1904-1994).

La figura de Altamira tiene en esta materia un lugar principal, no solo por provenir de una generación anterior y por prolongar su actuación en el período que nos ocupa. Se trata de una personalidad sobresaliente, que ejerció un claro influjo en los comienzos del americanismo científico que empezó a visualizar desde su cátedra de Historia del Derecho Español en la Universidad de Oviedo. Él siguió de cerca los movimientos de esa orientación que se desarrollaban en otros países de Europa y América. Tuvo así oportunidad de realizar viajes y visitas a distintos países. En nuestro caso, cabe prestar especial atención a su visita y recorrido americano, con principal estadía de cuatro meses en la Argentina que hizo en 1909-1910, cuando tenía cuarenta y dos años de edad. En los últimos años se ha conocido mejor la personalidad de este maestro a través de nuevas investigaciones que han sacado a la luz rasgos importantes de esa misión americanista. Se destaca asimismo la orientación que dio a los estudios desde su cátedra y también a través de las revistas americanistas que dirigió y de la edición de colecciones documentales.

\section{En torno a la historiografía americanista}

La formación de un concepto genérico de americanismo que respondiera a una demanda política y cultural diversa exigió distintos pasos que en España había asomado como un movimiento histórico-cultural a raíz de las celebraciones del IV Centenario del Descubrimiento de América en 1892. Con tal motivo hubo diversas ciudades que extendieron su actividad a las primeras décadas del siglo $\mathrm{XX}$, en ideas y proyectos historiográficos que difundieron la denominada «historia legitimadora», con autoridad avalada por la Real Academia de la Historia. Estos esfuerzos básicos necesitaron 
de nuevas ideas e impulsos para alcanzar una etapa plenamente científica. Así, exigió tiempo y trabajo lograr imponer la idea de que, por ejemplo, el Archivo General de Indias, en vez de ser un depósito de papeles de uso solo para fines políticos y burocráticos, fuese una entidad de libre acceso para la investigación histórica. ${ }^{2}$

La historiografía americanista adquirió estatuto científico cuando quedó vinculada a la cátedra universitaria y al seminario histórico. Ello ocurrió a partir de las primeras décadas del siglo XX y tuvo al principio su centro de desarrollo en las cátedras de Historia de América de la Universidad Central de Madrid, donde se desempeñaron como catedráticos Rafael Altamira y Antonio Ballesteros Beretta, que se convirtieron así en los primeros profesores que empezaron a transmitir un nuevo modelo científico de estudios e investigaciones que se consolidó con la formación de discípulos. Para cursar la disciplina de «Historia de América» antes de 1930 se debía acudir a Madrid, en esas cátedras que eran bastante diferentes en cuanto a la personalidad del profesor y desarrollo del curso. Ambos llegaron a la cátedra por distintos caminos, con semejanzas en el método pero con diferencias en sus experiencias personales.

Estos profesores, según se les ha reconocido, fueron principales impulsores de la historiografía americanista universitaria española. Ocuparon diferentes tipos de cátedras, a las que cada uno tuvo una forma de acceso distinta. Ballesteros, con estudios de Derecho y Filosofía y Letras, tuvo en un primer momento dedicación a los asuntos jurídicos. En 1914 se hizo cargo, por acumulación, de la asignatura «Historia de América» que se dictaba en la Facultad de Filosofía y Letras. El programa de la materia era de carácter narrativo, con primacía de los factores políticos e incluyendo cierto trazado institucional. ${ }^{3}$ Además, Ballesteros incluía algunos temas de historia americana en su programa de «Historia Española» en la licenciatura.

Cuando Altamira recordaba la existencia de estas dos cátedras de Historia de América, consideraba a la de Ballesteros de carácter «histórico-documental» y a la suya como de «índole especial». Es importante atender a esta diferencia. La cátedra asignada a Altamira fue una creación que se hizo también en 1914 bajo la denominación de «Historia de las Instituciones Civiles y Políticas de América», establecida como materia común, aunque de libre elección, en el doctorado de las Facultades de Derecho y de Filosofía

2 Vélez, 2007, 49, 62ss, 89 y 140.

3 Ibidem, 220-221. 
y Letras de la Universidad de Madrid. Esta cátedra fue desempeñada por Altamira desde entonces y hasta su jubilación en 1936.

Cursaban con Altamira jóvenes doctorandos procedentes de diversas universidades españolas y de países hispanoamericanos, algunos de los cuales iniciaron una interesante experiencia acercándose al conocimiento de la legislación indiana y alcanzaron a producir unas primeras tesis doctorales sobre la materia. Las clases de Altamira no eran lecciones magistrales sobre la base de un programa orgánico, sino desarrollos en torno a temas de investigación que iban surgiendo de acuerdo a los intereses de los doctorandos y al impulso creativo que provenía del maestro. Estaban, sin duda, destinadas a despertar en ellos y encauzar inquietudes intelectuales, adiestrándolos en problemas metodológicos y de investigación histórica y jurídica.

En tal sentido, Altamira abrió importantes caminos a la investigación de las ciencias sociales y humanas, pero de modo particular lo hizo en el campo de la historia de la colonización española, en su enfoque histórico institucional y jurídico. Su magisterio universitario encontró seguidores de relieve en un primer momento, como sus discípulos españoles José María Ots Capdequí, Juan Manzano Manzano y Javier Malagón; el mexicano Silvio Zavala y el chileno Aníbal Bascuñan Valdés, entre otros.

La historiografía americanista se extendió a la Universidad de Sevilla en las primeras décadas del siglo XX, empezando con la historia del arte colonial. En 1931 se estableció el Centro de Estudios de Historia de América (CEHA) en la misma Universidad bajo la dirección técnica de José M. Ots, que ya era catedrático de Historia del Derecho Español en Sevilla y dirigía el Instituto Hispano-Cubano de Historia de América, que alcanzó una breve época de esplendor antes de la guerra civil. Como acontecimiento más representativo de estos años cabe mencionar el XXVI Congreso Internacional de Americanistas celebrado allí en 1935, como culminación de una serie de reuniones internacionales de esa índole que se venían realizando desde varios lustros atrás. ${ }^{4}$

\section{La visita de Altamira a la Argentina (1909)}

La figura de Altamira tiene una trayectoria distinta a la de otros profesores en el tema que estamos considerando. Proviniendo de una época

4 Ibidem, 354-358. 
anterior, prolongó su actuación e influjo gracias a su personalidad sobresaliente y capacidad creativa, que ya había demostrado como profesor de Historia del Derecho Español en la Universidad de Oviedo. Antes de su definitivo asentamiento en Madrid, Altamira, entre otras actividades académicas, ya se destacaba por el cultivo de su idea americanista, que culminó con una extendida visita de nivel académico que hizo al continente americano en los años 1909 y $1910 .{ }^{5}$

De modo especial su visita cobró más trascendencia por su itinerario en la Argentina, que se desarrolló entre julio y septiembre de 1909. Dictó cursos en las universidades de La Plata, Buenos Aires y Córdoba, y mantuvo un provechoso contacto con historiadores y juristas, según lo vienen demostrando las últimas investigaciones que se están realizando. ${ }^{6}$ En esa ocasión, además de un curso sobre Metodología de la Historia dictado en la sección Letras de la Facultad de Derecho y Ciencias Jurídicas de la Universidad de La Plata, le fue encargado otro curso sobre Historia del Derecho en la Facultad de Derecho y Ciencias Sociales de la Universidad de Buenos Aires. ${ }^{7}$

El éxito académico y social de este último curso siguió la misma senda que el anterior, pero tuvo un resultado más concreto en cuanto al debate entre los partidarios de una orientación profesional de los estudios jurídicos frente a quienes postulaban una formación científica y humanista más diversificada, que abriera un área de estudios donde la historia del derecho tuviese, en la enseñanza e investigación, un amplio campo de acción formativa en los futuros abogados. Entre las razones para defender la utilidad práctica de la materia aparecía la necesidad de incorporar el conocimiento del derecho consuetudinario para establecer un marco nacional en la solución de los conflictos de propiedad ante los tribunales y en general para orientar conductas jurídicas.

En este sentido, Altamira encontró en la órbita de la Universidad de Buenos Aires un grupo de juristas bien predispuestos al diálogo $-\mathrm{y}$ también a la crítica - como Antonio Dellepiane - con notorias afinidades-, Estanislao Zeballos, Juan Agustín García, Ernesto Quesada y Carlos Octavio Bunge - con ciertos desencuentros-, entre otros. Si bien el diálogo efectivo con Altamira no pudo ser tal vez muy profundo, cierto es que según

5 Malagón y Zavala, 1971. Rafael Altamira, 1987. Alberola, 1988.

6 Pelosi, 2005.

7 Prado, 2010; 2015. 
sabemos el maestro español mantuvo siempre hasta los últimos años de su vida el recuerdo inolvidable de esos meses de la Argentina en vísperas del Centenario. Ello se patentiza en la figura de Ricardo Levene, a quien apenas pudo conocer de modo accidental en ese momento, ya que por edad no había entonces ingresado en aquel círculo mayor de juristas. Lo haría, sin embargo, unos años más tarde a través del diálogo epistolar constituyéndose en el principal receptor de esa influencia que había dejado el maestro español, según veremos.

Durante su visita Altamira no solo mantuvo relación con juristas sino también con otras personalidades de distintos ámbitos del saber, de la política o de la administración. No es exagerado sostener que esta visita americana —incluyendo otros países, como México- ${ }^{8}$ significó un enriquecimiento intelectual y humano que Altamira capitalizó en su regreso a España para dar un giro importante a su propia vida de trabajo y afinidad intelectual, que lo llevó finalmente, luego de un breve tiempo intermedio, a asumir en 1914 la ya mencionada cátedra madrileña de Historia de las Instituciones Civiles y Políticas de América, desde la cual obraría con plenitud en la formación y propagación de lo que ha sido llamado el «Derecho indiano» de Rafael Altamira.

\section{El entronque hispano-argentino de la época}

Una rápida mirada sobre lo que ocurría en esa época en la Argentina y especialmente en Buenos Aires ayudará a comprender mejor la situación y el clima intelectual en que se vivía. Se puede así observar que el cultivo científico de la historia empezaba a ocupar un lugar entre las humanidades o ciencias del espíritu y se consolidaba a través de cátedras universitarias, centros de investigación y grupos de nuevos historiadores. En tal sentido pueden señalarse como hechos determinantes la creación de la Facultad de Filosofía y Letras de la Universidad de Buenos Aires en 1893, con su sección de Historia en 1905; y la fundación de la Junta de Historia y Humanística Americana (1893 y 1901). La primera de ellas dio marco a la aparición de la denominada «Nueva Escuela Histórica» (1916), que sin romper con la tradición historiográfica anterior -Mitre, Groussac, Juan A. García-

8 Altamira, 1993. 
reformuló ciertos principios metodológicos y estableció problemas y criterios que permiten marcar los contornos estables de una disciplina con cultivadores profesionales. La denominación de «Nueva Escuela» con que la bautizó Juan A. García — que pertenecía a una generación anterior- dio formalidad a ese suceso. En 1921 aquella sección «Historia» se transformó en el Instituto de Investigaciones Históricas, bajo la dirección de Emilio Ravignani, con amplias colecciones de estudios y documentos de historia argentina y americana. En la Universidad de La Plata donde la cátedra de Historia Argentina y Americana fue encargada en 1913 a Ricardo Levene, el campo de estudios se amplió con otras cátedras y seminarios en la década de los años veinte.

Estos dos ámbitos universitarios fueron los que mejor se perfilaron entonces, y sus líderes intelectuales - Levene y Ravignani- se convirtieron en cabeza de la mencionada Nueva Escuela. Entre las cuestiones que planteó este movimiento renovador sobresalió el de alcanzar una interpretación integral del pasado nacional. Dentro de estos horizontes cobró relieve el campo disciplinario llamado entonces como «Historia colonial». ${ }^{9}$

Cabe agregar a estos ámbitos universitarios, los archivos y bibliotecas públicas ya existentes en el siglo anterior, que junto con otros nuevos repositorios fueron puestos a disposición de los investigadores. También es preciso señalar la existencia de varias entidades que agrupaban a eruditos e historiadores, entre los cuales tuvo una notoria hegemonía intelectual la Junta de Historia y Numismática Americana que en 1938 se transformó en la actual Academia Nacional de la Historia. ${ }^{10}$

La edición de fuentes documentales y la publicación de nuevos estudios de alto rigor científico actualizaron la bibliografía histórica, tanto mediante ediciones de esos centros, como de editoriales comerciales. De igual modo, cabe aquí recordar a las revistas universitarias y académicas, que por entonces animaron el campo del saber histórico.

Así, dentro de este cuadro estimulado con nuevas perspectivas y enfoques surgió en la Facultad de Derecho y Ciencias Sociales, la necesidad de abrir las investigaciones al «Derecho colonial». Es importante recordar en este punto que los Anales de esta Facultad y la colección de publicaciones que bajo su patrocinio tuvo lugar en estas décadas iniciales del siglo, dio

9 Devoto, 1993, I, 45-78.

10 Academia, 1995, I, 23-53, 123 ss, 219-234 y 251-268. 
lugar especial a las contribuciones histórico-jurídicas y dentro de ellas a las relativas a la época hispana.

Asoman así en estas páginas, además de Levene y Ravignani, otros autores, cuyos nombres son reconocidos como protagonistas de ese movimiento renovador de la historiografía hispano-argentina. Ellos son, entre otros, Enrique Ruiz Guiñazú, Rómulo Carbia, Diego Luis Molinari, Jorge Cabral Texo, José Torre Revello, Guillermo Furlong y Roberto Levillier. Todos ellos establecieron un centro de atención en el Archivo General de Indias con investigaciones personales o dirigidas para encontrar los orígenes de la nacionalidad. ${ }^{11}$

Este movimiento ocurre entre fines del siglo XIX y primeras décadas del XX, con prolongación en los lustros siguientes, según sean los casos y requerimientos. Es la época en que se constituye en la Argentina, como en otros países, el denominado «conocimiento social». En el desenvolvimiento de las «ciencias sociales» es donde aparecen estrechamente vinculados la historia y el derecho, con la fuerte presencia de una disciplina nueva, la sociología, que se erigía por entonces en el núcleo duro de esas ciencias sociales, con una investigación básica y otra aplicada, en una distinción no siempre bien percibida.

Es en esta misma época cuando se percibe la apertura de un espacio de estudio cultural e intelectual hispano, que involucra a España y a los países hispanoamericanos en una nueva relación entre sí que tendía a superar la situación de «desencuentro» o indiferencia que, en la esfera pública, había dominado durante los tiempos posteriores a la emancipación. La etapa del «reencuentro» tiene raíces y motivaciones, comunes o particulares, según los países y campos intelectuales. Se fueron así formando diversas vertientes de un hispanismo, fuertemente teñido a veces de componentes ideológicos o de elementos provenientes de diversos campos intelectuales como la filosofía, las letras, las bellas artes, etc. Precisamente una de esas exteriorizaciones, manifestada en la unión de dos campos, la historia y el derecho, es la que se intenta presentar en este trabajo. Plasmado así dentro del espacio historiográfico hispanoamericano, su toque de atención está puesto en la formación hispano-argentina que fue muy fuerte en las décadas siguientes. $^{12}$

11 Molina, 1955, 195 ss.

12 Academia, 1995, I, 208-209. 


\section{Sobre el encuentro de Altamira con Levene. Amistad y paralelismo intelectual}

Cuando Altamira hizo su visita a la Argentina, Levene - por razones de edad - no había alcanzado a ubicarse en el círculo de juristas e historiadores que rodearon al visitante, como lo he destacado. Sin embargo, cabe suponer que Levene, entusiasta lector de los libros del catedrático español, asistió a sus cursos y conferencias y tuvo contactos con él, dada su condición de secretario de la Asociación Nacional del Profesorado, entidad que agasajó al visitante y lo distinguió con la designación de socio honorario.

Además, conocemos a través de la información periodística de la época que Altamira, recién llegado a Buenos Aires, estuvo presente en la conferencia que el joven Levene dio en dicha Asociación el 13 de julio sobre «Los orígenes de la Revolución Argentina de 1810». El salón estaba colmado de público que, en su mayoría, eran profesores universitarios y secundarios. El único mencionado por la prensa, como invitado especial, era precisamente Altamira.

Tiempo después y una vez ya consolidada su investigación en el profesorado de la Universidad de Buenos Aires, Levene le hizo llegar sus primeros trabajos sobre el período hispano. Entre ellos, un estudio sobre la economía virreinal que se había publicado como introducción a dos volúmenes de la colección de Documentos para la historia argentina, editados por la Facultad de Filosofía y Letras. La recepción de dicho estudio suscitó la carta de don Rafael, fechada en Madrid el 17 de noviembre de 1915. Es la primera del epistolario que conocemos. Le expresaba en la misma el valor que tenía dicho trabajo para los estudios que desarrollaba en su cátedra madrileña y a su vez anunciaba que le haría llegar las monografías americanistas que se fuesen publicando, ya que era necesario para el progreso de un conocimiento la comunicación constante entre todos los que trabajan en un orden determinado de materias.

La mayor sorpresa de Altamira, sin embargo, ocurrió poco después cuando Levene le hizo otro envío: su lección titulada Introducción al estudio del Derecho indiano, impresa en 1916. La respuesta contenía párrafos que marcaban un rumbo común para la tarea y señalaban coincidencias en la enseñanza de la materia en Buenos Aires y Madrid. Así, Altamira encontraba que sus primeras lecciones del curso de Instituciones de América, repetidas en esos años - 1914, 1915 y 1916- parecían ser un eco 
de sus conceptos, ya que no de su palabra. «Por ello — agregaba - y para que viesen mis discípulos que no es solo un español quien dice esas cosas, les leí en una de mis cátedras del pasado mes de noviembre, la lección de usted, marcándole los pasajes que más especialmente coinciden con los apuntes que ellos tienen de los referidos años». Luego de informarle sobre sus planes de trabajo en la formación de un grupo de americanistas, Altamira concluía con este firme augurio: «Unidos los esfuerzos de ustedes y de nosotros, guiados todos por la serena búsqueda de la verdad es de creer que dentro de algunos años la historia colonial que se conozca difiera un mundo de la que hasta ahora se ha propalado. A usted le tocará buena parte de esa renovación».

El texto de la carta que contenía tan singular predicción tuvo difusión pública en su época a través de los Anales de la Facultad de Derecho y Ciencias Sociales de Buenos Aires. Una cálida amistad unió desde entonces a ambas figuras como se refleja en el epistolario que conocemos. Además se expresó a través de prólogos y dedicatorias de libros y en recíprocas reseñas bibliográficas de los estudios que cada uno producía. ${ }^{13}$

Puede sorprender la notable predicción que Altamira hacía a su joven corresponsal cuando este aun no había publicado las Notas para el estudio del Derecho Indiano (1918) y la Introducción a la Historia del Derecho Indiano (1924), que produjeron una temprana consagración de su labor intelectual. Altamira utilizó y recomendó a sus discípulos y alumnos este último libro a lo largo de los años treinta y cuando en 1938 había quedado aislado de sus libros para continuar sus investigaciones, decía que solo le quedaban los guiones de sus clases y una edición más moderna de la Recopilación de 1680. Por eso le agradecía a su amigo que le hubiera podido remitir un nuevo ejemplar de aquella Introducción.

Esta amistad estaba unida a un «paralelismo intelectual» tal como lo expresaba el catedrático español, al decir que ello consistía en que «... sin que mediase ningún conocimiento ni comunicación personal entre Levene y yo y sin que cupiese siquiera la posibilidad de un saber directo y recíproco de nuestros trabajos de cátedra, puesto que nada de ellos había sido publicado, llega a mis manos la Introducción al estudio del Derecho Indiano [1916] y veo con satisfacción que cada uno de nosotros, Levene en Buenos Aires, yo en Madrid, al estudiar el mismo asunto, habíamos coincidido en criterios, puntos de vista y conclusiones generales, como si hubiéramos

13 Tau Anzoátegui, 1990. 
sido compañeros de trabajo en un mismo seminario o laboratorio de investigaciones».

La correspondencia continuó siendo la vía de comunicación que ellos pudieron utilizar para transmitir sus ideas y proyectos de investigación durante la década del cuarenta hasta el fallecimiento de Altamira.

Los diálogos epistolares entre Altamira y Levene - como he señalado en un trabajo anterior- ${ }^{14}$ fueron intercambios de reflexiones y proyectos que generaron un ámbito intelectual atractivo por su calidad científica y por su dimensión humana. Abrieron así vías de comunicación a discípulos de distintas procedencias geográficas y fueron cimientos poderosos de una acción colectiva que se transmitió a sus seguidores en las décadas siguientes.

\section{La «institución» como vocablo clave en el pensamiento y la acción de Altamira}

El vocablo «institución», que puede ser abordado y utilizado de diversos modos, tiene un particular interés en nuestra materia para insertarlo en la historia de la colonización española en América. Ya apareció en la denominación de la cátedra creada para Altamira en 1914 y seguramente por indicación suya: «Historia de las instituciones políticas y civiles de América». Fue incorporada a los estudios del Doctorado de las Facultades de Filosofía y Letras (sección Historia) como materia de elección libre y se indicaba como parte importante de la misma el estudio de las instituciones coloniales españolas. ${ }^{15}$

Podría así sostenerse que Altamira introdujo con cierta novedad el término «institución» para designar a las series de fenómenos y organizaciones que tocaban a la raíz social, jurídica y económica de la vida americana, sin omitir los hechos políticos, pero sin quedar atrapado por el mero acontecer del relato histórico. Es probablemente esto lo que intentó concebir y aplicar al estudio de la colonización española. Logró hacerlo con una relatividad propia de la materia pero al mismo tiempo con la seguridad de ofrecer un enfoque innovador apoyado libremente en los nuevos conocimientos y doctrinas que efectivamente se estaban desenvolviendo en la sociología

14 Tau Anzoátegui, 1998.

15 Vélez, 2007, 190-203. Ots Capdequí, 1966. 
y filosofía contemporáneas. Despuntaba entonces una concepción social del derecho, que intentaba exponerse históricamente.

Este criterio aparecía como un modo novedoso de acercarse al estudio de la historia política y social de la colonización española. La postura abría caminos pero también planteaba nuevos problemas y dudas, sobre todo cuando se pretendía alcanzar una visión abarcadora de todo el proceso denominado «colonial».

Al mismo tiempo Altamira se mostraba crítico frente a quienes intentaban reducir el derecho indiano a las cédulas y otras formas de legislación regia y solo por excepción acudían a algunas ordenanzas virreinales y autos del Consejo de Indias. Él apuntaba a la utilización de tipos documentales alternativos como los registros cedularios, el Diccionario de Ayala u otras colecciones que permitieran al investigador ahondar ese conocimiento jurídico en sus raíces sociales. La institución indiana era, pues, entendida en el sentido más profundo posible con la intención de alcanzar el «derecho vivido» más que «el hecho legislativo». ${ }^{16}$

La utilización de la voz «institución» por parte de Altamira puede considerarse aceptable, sobre todo para su planteo dentro de una disciplina en formación en el área y nivel de estudio que tenía asignada. Puede, en fin, servir también de interesante precedente para el desarrollo posterior que tuvieron los estudios de Historia de las Instituciones Indianas y de Historia del Derecho Indiano, tal como fueron delineados desde el punto de vista metodológico, con otro alcance y perspectivas, por historiadores como Alfonso García-Gallo y otros posteriores. ${ }^{17}$

La «institución» es vocablo de un rico y complejo contenido que aparece con cierta permanencia en el léxico histórico, jurídico y político. Es preciso aceptar sus variantes, sin alcanzar una única definición, pero sobre todo fortalecer su presencia en las aulas y en el seminario histórico.

\section{El enfoque institucional de Ots Capdequí}

Una interesante aplicación de esta concepción de Altamira fue practicada por José María Ots Capdequí, su principal discípulo. Catedrático de Historia del Derecho Español en la Universidad de Sevilla, Ots orientó su

16 Vélez, 2007, 432ss.

17 García-Gallo, 1967, 13ss.; 1970, 15-24. Tau Anzoátegui, 2010, 105ss. 
labor de investigación hacia el americanismo, con dedicación casi exclusiva. Desde muy joven, sostuvo que la legislación indiana debía ser incorporada a la enseñanza del derecho español. Estaba pues en el meollo donde se incubaba este enfoque. ${ }^{18}$

Ots hizo aplicación del criterio institucional en la visita que realizó a la Argentina en 1934 para dictar cursos y conferencias en las áreas de Humanidades y de Filosofía y Letras de las Universidades Nacionales de La Plata y de Buenos Aires, que fueron completadas con lecciones prácticas de seminario a egresados y estudiantes. Su actividad dominante estuvo constituida por las conferencias platenses sobre «Las instituciones sociales de la América Española en el período colonial», tema que adquirió mayor notoriedad y perduración cuando se convirtió en título del libro que editó la misma Universidad Nacional de La Plata, que presidía Ricardo Levene.

Temas principales de esa visión de Ots fueron entonces las clases sociales - tema que incluía la condición jurídica de los indios—, la familia, la propiedad y el régimen municipal, siempre unidos en su expresión al precedente castellano. También en este ciclo de disertaciones incluyó el régimen político y administrativo y las bases económicas de la colonización.

A través de estas disertaciones y cursos, que se extendieron a otras universidades e instituciones históricas del país, se puede apreciar una interesante aplicación de aquellas ideas de Altamira, pero también es dable observar la introducción por parte de Ots de un elemento nuevo, al encuadrar su tarea dentro de la moderna historiografía del derecho español, que aparecía entonces representada por Eduardo de Hinojosa y su escuela. Precisamente este fue el tema que eligió para su disertación en Buenos Aires, cuando la Junta de Historia y Humanística Americana, presidida por el mismo Levene, lo recibió como miembro correspondiente en España. Ots integraba, ya desde la fundación del Anuario de Historia del Derecho Español en 1924, el grupo de catedráticos españoles que, bajo la conducción de don Claudio Sánchez Albornoz, impulsaban este emprendimiento editorial y mantenían relación directa con historiadores y juristas hispanoamericanos.

$\mathrm{Al}$ producirse en España la guerra civil, Ots tuvo que afrontar un doloroso exilio entre 1939 y 1952. En esos tiempos difíciles continuó, sin embargo, desarrollando la enseñanza e investigación del derecho indiano desde su cátedra de la Universidad Nacional de Colombia, en Bogotá.

18 Vélez, 2007, 226-228. Malagón, 1977. Peset, 1990. 
El enfoque institucional de José M. Ots se mantuvo en sus posteriores trabajos y sobre todo se observa en su principal obra de conjunto, el Manual de Historia del Derecho Español en América y del Derecho propiamente indiano, que recogió sus lecciones de cátedra y se publicó en 1943 en Buenos Aires, en la colección del nuevo Instituto de Historia del Derecho Argentino dirigido por Ricardo Levene, con un sustancioso prólogo de este.

Según expresaba Ots, se trataba de la «proyección en las Indias del Derecho castellano peninsular y nacimiento y desarrollo del Derecho propiamente indiano». En cuanto a sus predecesores en la materia, destacaba la existencia de dos obras que le habían sido de gran utilidad: la Introducción a la Historia del Derecho Indiano de Ricardo Levene de 1924 y las lecciones de un curso sobre instituciones de derecho público hispano-americano explicado en Sevilla por el profesor norteamericano Clarence H. Haring. La obra de Levene — según decía — representaba el «primer intento, felizmente logrado, de orientar sistemáticamente a los universitarios americanos en el estudio histórico del derecho colonial»; y agregaba un juicio más contundente sobre lo que representaba la labor universitaria de Levene en el campo del derecho indiano, al situarla en el mismo nivel a la que estaba realizando el maestro Altamira desde la cátedra madrileña.

Sostenía Ots que el Manual se presentaba desde el punto de vista español, pero pensando en los estudiosos americanos. Y además que la historia institucional de la colonización española en América debía ser construida en colaboración con historiadores españoles y americanos. De igual modo establecía que los legajos documentales del Archivo General de Indias debían ser contrastados con la realidad viva de América y con los papeles guardados en los archivos locales.

Ots realizó una intensa labor de colaboración en obras de conjunto. Precisamente en lo que concierne a la materia que aquí tratamos se destaca el volumen titulado Instituciones, de su autoría, pero que formó parte de una obra general sobre Historia de América y de los pueblos americanos, dirigida por Antonio Ballesteros y Beretta, publicada en 1959. Al encontrarse este volumen integrado en una edición colectiva, no aparece prólogo ni página introductoria explicativa acerca del título que ostenta. Dada su estructura histórico-jurídica, se evidencia un afán por colocar ese vocablo como un enclave necesario dentro de la denominada Historia de América, sin la obligación de una mayor precisión.

Dentro de la magnitud de la obra de José María Ots, apenas insinuada en las páginas anteriores, y que recorrió distintas sendas historiográficas, 
tal vez no sea vano ocuparme como apunte final de la misma, de una breve relación que escribió en 1955 para el X Congreso Internacional de Ciencias Históricas celebrado en Roma. En este escrito, de título amplio «Sobre la historia de la colonización española», la pluma de Ots luce con la serenidad y madurez de un antiguo conocedor del tema. Traza, así, un rico panorama de la materia, profundo y abierto a nuevas indagaciones bajo la especial y necesaria directiva de estudiar «los perfiles doctrinales de las instituciones y sus precedentes peninsulares», como también el grado efectivo de vigencia y los factores económicos y sociales que las condicionaron. Como en todo extenso trayecto histórico, los tiempos y las circunstancias merecían su especial recomendación.

En fin, como labor fundamental, Ots Capdequí sostenía la necesidad de estudiar «lo que representó la proyección institucional del Estado español en sus dilatados dominios ultramarinos, ya que la preocupación por lo jurídico y el logro de amplias estructuraciones político-administrativas, económicas y sociales, es, sin disputa, lo que más y mejor caracteriza a la obra colonizadora desarrollada en el continente americano por la España peninsular». ${ }^{19}$

\section{En el estudio del derecho indiano: la historia de las recopilaciones y los cedularios}

Una preocupación permanente de Altamira durante su largo ciclo docente fue la de penetrar en el conocimiento de la legislación indiana bajo sus diferentes formas. Especialmente encontró en la Recopilación de 1680 un camino para conocer a fondo esa legislación, su origen, aparición y transmisión de su contenido. La idea lo fue llevando con el tiempo a separar ese estudio en dos cuestiones distintas: por una parte, la historia completa de esa legislación indiana; y por otra, la preparación de una edición crítica de la Recopilación. Para ello contaba, en su retiro de Bayona en 1938 — según él mismo lo expresaba—, solo con los guiones de sus clases madrileñas y con un ejemplar de la Recopilación de 1680 en su reedición de 1791. Era un asunto que asomaba con fervor cuando las preguntas y problemas crecían en la mente de Altamira y el material de investigación, en archivos y bibliotecas, estaba desgraciadamente alejado de sus posibilidades de consulta.

19 Ots Capdequí, 1992, 97-108. 
A pesar de los problemas que enfrentaba, Altamira decidió avanzar en la composición de una obra a la que, de modo ambiguo, dio por título Análisis de la Recopilación de las Leyes de Indias de 1680, incluyéndola en una ambiciosa colección personal de «Estudios sobre las fuentes de conocimiento del derecho indiano», que solo parcialmente pudo llevar adelante.

Esta obra, que adolecía de una cierta flojedad estructural, tuvo la virtud de proporcionar una línea de investigación a una generación de nuevos estudiosos y críticos. Eran muchas las preguntas que se podían plantear. El propio Altamira percibió la dificultad de encontrar la historia de dichos textos legales.

El análisis de Altamira avanzó más en lo que pretendía ser «una edición crítica», atendiendo a cuestiones como el origen, forma, contenido y naturaleza de ciertos textos de la Recopilación, abriendo un campo de estudio atractivo para el investigador y permitiendo alcanzar una mejor lectura de dichos textos. Al mismo tiempo se lograba alejar una visión enteramente legalista del derecho indiano.

El libro de Altamira fue finalmente editado en Buenos Aires en 1941, por el Instituto de Historia del Derecho Argentino, que dirigía Ricardo Levene, quien se empeñó en lograr la remisión de los originales desde Bayona por vía diplomática, en plena guerra mundial, para asegurarse un envío que se hacía dificultoso en esa difícil situación.

La obra apareció dedicada por el autor a Levene y con el auspicio de la Institución Cultural Española. En la «Advertencia» que suscribió Ricardo Levene se percibe un tono de cortesía y reconocimiento genérico a «la autoridad moral y científica del ilustre maestro de los historiadores hispanoamericanos», pero sin abrir juicio u opinión sobre la propia obra que se publicaba. Hay en este punto un evidente contraste con el prólogo que, en este mismo tiempo, hizo Levene para el libro de Ots Capdequí, que ya conocemos.

Pese al escaso éxito alcanzado por este libro, hay que reconocer que en esta línea de investigación abierta por Altamira se hicieron otros trabajos de interés. En lo relativo a la historia de la Recopilación sobresalió la figura de su discípulo Juan Manzano Manzano. ${ }^{20}$

Estudiando Derecho en la Universidad de Sevilla, Manzano conoció a Ots Capdequí y luego hizo la tesis doctoral en Madrid bajo la dirección de Altamira, abordando un tema de la historia de la Recopilación, que tanto

20 Pasamar y Peiró, 2002, 381-382. 
apasionaba a su maestro. Se incorporó más tarde a la cátedra de Altamira como profesor ayudante hasta alcanzar en 1940 la titularidad de la cátedra de Historia del Derecho Español en la Universidad de Sevilla. Altamira acertó en la elección de este discípulo suyo para desenvolver la investigación que tanto le preocupaba sobre la Recopilación de las leyes indianas. Ello exigía una larga tarea en el Archivo General de Indias principalmente. A esta materia se dedicó con tiempo y empeño el joven discípulo. Juan Manzano estuvo siempre en el recuerdo de Altamira en sus últimos años de vida, cuando se hizo difícil la comunicación entre ambos.

Luego de sus búsquedas en el Archivo de Indias y en otros repositorios documentales, que fue plasmando sucesivamente en trabajos parciales, Manzano pudo culminar la tarea mediante la publicación de la Historia de las Recopilaciones de Indias, en 1950. Esta obra aparecía dedicada a «mi maestro Rafael Altamira», a quien colocaba por encima de todos y subrayaba «al que en gran parte debemos lo que hoy somos y aun lo que podemos llegar a alcanzar». ${ }^{21}$

La investigación de Manzano era documentalmente muy completa y superaba vacíos y afirmaciones controvertidas. Estaba pensada y ejecutada en una línea que se apartaba de la de Altamira y era, si cabe, menos profunda y problemática, pero mucho más certera en cuanto se atenía a una sólida base documental, con la cual resolvía las más importantes cuestiones planteadas por la anterior historiografía. ${ }^{22}$

Años después, se publicó el segundo volumen de la obra que Manzano dedicó esta vez a Alfonso García-Gallo, quien ya se destacaba por su labor en esta misma línea temática de investigación. Reediciones posteriores han permitido transmitir ya, en 1981 y 1991, la obra completa de este cabal iushistoriador español sobre un aspecto central del derecho indiano.

Otra senda provechosa para penetrar en la legislación indiana fue el estudio de los cedularios, principalmente los existentes en el Archivo General de Indias. La tarea de formar un catálogo de los libros allí existentes fue una idea que tuvo algunos intentos en los comienzos del siglo XX. En la década del 1940, el maestro Altamira publicó un estudio titulado Los cedularios como fuente histórica de la legislación indiana, que abarcaba el concepto, clasificación y ubicación de las distintas clases de cedularios y de su importancia para el conocimiento de la legislación indiana.

21 Manzano, 1981, I, 16.

22 Ibidem, I, 9-16 y II, 9-11. 
En este punto aparece otra figura representativa, que siguió el camino de Altamira. Me refiero a Antonio Muro Orejón, nacido en Sevilla en 1904, quien, después de graduarse en Derecho, estableció contacto con los documentos del pasado cuando elaboraba su tesis doctoral en Madrid sobre el denominado «El nuevo Código de las Leyes de Indias» de 1776. Altamira fue uno de sus maestros. También se vinculó con Ots Capdequí. ${ }^{23}$

Muro Orejón obtuvo en 1946 la cátedra de Historia del Derecho Indiano, que estaba ubicada en la sección de Historia de América de la Facultad de Filosofía y Letras de la Universidad de Sevilla, desempeñándola hasta su jubilación en 1974. Esta labor se extendió a la Escuela de Estudios Hispano-Americanos y a la Universidad Hispanoamericana de Santa María de la Rábida, en donde desempeñó cargos directivos y colaboró en sus publicaciones. $^{24}$

Las puertas del Archivo General de Indias se abrieron para él, de modo que pudiera saciar sus inquietudes intelectuales y provocar el diálogo directo con las fuentes documentales. Es así que su mayor actividad se fue concentrando en el inventario, estudio y edición de fuentes inéditas. Apuntaba entonces hacia textos fundamentales del derecho indiano sin la pretensión de realizar una obra conjunta de ellas sino de hacer publicaciones independientes de las mismas.

Su aproximación al derecho indiano se produjo desde los documentos y no desde una construcción dogmática previa o desde un anticipado planteamiento conceptual histórico-jurídico. Establecía así, como he dicho, una suerte de diálogo con el propio documento. Esto significaba, como lo hacía el maestro Altamira, un encuentro muy particular que distinguía a este tipo de estudioso del que se limitaba a copiar o hacer simple relación del documento que tenía a la vista.

Aunque esta característica de la personalidad del profesor Muro pudo incidir en la extensión de su producción monográfica sobre las instituciones, García-Gallo apunta que su tarea de explicar las instituciones a sus alumnos le sirvió de base para preparar breves artículos que publicados en una importante Enciclopedia representaban un posible manual de derecho indiano. En cierto modo, este enfoque quedó plasmado en sus Lecciones de Historia del Derecho hispano-indiano que alumnos mexicanos suyos dieron a conocer en 1989.

23 Pasamar y Peiró, 2002, 437-438.

24 García-Gallo, 1974. Homenaje al Dr. Muro Orejón, 1979. Tau Anzoátegui, 1994. 
La labor docente y producción documental de Muro Orejón apuntó de manera principal a resaltar la importancia excepcional que tenían los cedularios indianos. En el último trimestre de 1949 dictó un curso monográfico sobre «Los Cedularios en la Historia del Derecho Indiano», en el cual destacó el valor de los cedularios del Supremo Consejo de Indias como los únicos oficiales que contenían la totalidad de las disposiciones legales promulgadas para las provincias indianas desde el Descubrimiento de América hasta la Emancipación de la Corona. Eran pues los únicos para conocer de manera fehaciente tan vasta y completa labor legislativa de general observancia.

Fue la obra en la que Antonio Muro puso más empeño, con el auxilio de alumnos de su cátedra, siguiendo en esto el ejemplo del maestro Altamira. Así, aparecieron discípulos y colaboradores de este emprendimiento al que transmitió su espíritu y avizoró su continuidad, ya que evidentemente trascendía, dada su magnitud y complejidad, la posibilidad de que la abarcara alguien en solitario.

En esta materia el fruto personal alcanzado por Antonio Muro fue apreciable en la construcción documental de los volúmenes Cedulario Americano del siglo XVIII, cuya edición, estudio y comentarios impulsó él mismo. En ellos se advierte sutilmente el encuadre institucional que hacía de la materia cuidadosamente elegida, acompañada de referencias, datos y comentarios que apoyaban la labor de los investigadores.

Si bien el propósito del profesor Muro fue completar todo el período hasta 1800, no pudo hacerlo íntegramente y el tercer volumen alcanzó solo a 1746. El cuarto quedó en elaboración. Los diversos problemas y dificultades que se fueron presentando en su desarrollo, así como la forma de trabajo minucioso y no conformista adoptada por el autor provocaron demoras en el tratamiento de algunas cuestiones que se suscitaban e impidieron la finalización de las tareas previstas, tal como lo había originariamente proyectado.

\section{Epílogo}

Una lectura de los primeros volúmenes del Anuario de Estudios Americanos, que empezó a publicarse en 1944 bajo el impulso de un destacado grupo de investigadores, puede ofrecer un panorama de la aceptación que encontró aquella orientación dada por Altamira y Ots Capdequí para el 
estudio de la colonización española en América, sobre la base de las instituciones y de la legislación indiana.

Altamira formaba discípulos a través de sus clases y seminarios, de sus escritos y libros, algunos notorios y otros menos determinantes. Su mismo estilo o método de la clase establecía ese tipo de relación que resulta difícil, por no decir imposible, de acotar y definir. Sin embargo, de este magisterio se puede deducir una fuerte influencia de su pensamiento y acción, ya directa o indirecta, que orientaba el propio presente y los tiempos siguientes. Así fue, por ejemplo, su insistencia en que discípulos y alumnos concurrieran al Archivo General de Indias —donde él no pudo hacer estadías científicas - e hicieran indagaciones en las líneas documentales adecuadas al proyecto de investigación en curso. Los casos de Manzano y Muro Orejón, que hemos tratado en estas páginas, son elocuentes en este sentido.

La discusión o debate metodológico posterior seguramente disminuyó el eco proveniente de las enseñanzas de Altamira, pero quedó en gran parte su espíritu impregnado en los nuevos desarrollos. La historia de las instituciones adoptaría nuevos criterios, pero sin quedar desplazado ese espíritu legado por el maestro español.

Es cierto que Altamira no alcanzó a realizar una obra abarcadora de las instituciones indianas. El mismo método aplicado en sus clases como catedrático fue, como vimos, más dirigido a la fase de investigación que a culminar en un libro de conjunto con fines generales o docentes. En cambio, afortunadamente pudo establecer firmes directivas sobre la investigación, como la documentación que cabría ser objeto de atención y también susceptible de incorporar a las colecciones documentales, como él mismo pudo ejecutarlo en la dirección de una de ellas.

La presencia de una temática que aborde renovadamente la historia de América con criterio científico a la luz de la colonización española se percibe en el Anuario, como también en otras publicaciones de la Escuela de Estudios Hispano-Americanos, con el tratamiento que se hace de ciertas instituciones. Para mencionar algunos ejemplos concretos se pueden considerar interesantes artículos, tales como «El Protector de Indios», «La avería en el comercio de Indias», «Las instituciones canónicas en el Derecho indiano», «Las instituciones de naturales en el derecho conciliar indiano», «La visita como institución indiana» (canónica y civil), «Los Protomedicatos en Indias», «El Virreinato», «Juntas asesoras de teólogos», etc. A ello agregamos trabajos sobre juristas indianos, entre los cuales se destacan los relativos a las obras e ideas de Juan de Solórzano. 
Siempre dentro del mismo campo de estudio, cabe consignar el especial interés que despiertan algunas leyes fundamentales del siglo XVI, de las cuales se hacen estudios y ediciones críticas, como las Leyes Nuevas de 1542-1543. Asimismo, merecen particular atención las Capitulaciones y las Ordenanzas de Indios, como también las Bulas de Alejandro VI y las Encíclicas.

Estos y otros estudios y ediciones críticas estuvieron a cargo de reconocidos investigadores, entre los cuales cabe mencionar a Manuel Giménez Fernández, Guillermo Céspedes del Castillo, Manuel Gutiérrez de Arce, Francisco Javier de Ayala, Antonio Rumeu de Armas, Constantino Bayle S.J., Luis Alonso Getino O.P., Vicente Palacio Atard y Pedro Leturia S.J. Mención especial merece Antonio Muro Orejón, como directivo de la revista y autor de aportes documentales. La labor hispana del alemán Ernesto Schäfer y del peruano Guillermo Lohmann Villena, muy destacada en ambos casos, se incorpora a este grupo inicial de colaboradores del Anuario de Estudios Americanos.

Estos apuntamientos y notas, que constituyen el sostén del presente ensayo, requieren de una mayor atención y de ciertas posibilidades de desarrollo que no es posible incluir en este espacio. Solo he intentado sugerir una senda de indagación, aun no suficientemente explorada, a través de la aplicación del criterio institucional, que sirve para entender con más amplitud y profundidad la historia de la colonización española en América.

Recibido el 26 de septiembre de 2018

Aceptado el 10 de octubre de 2018

\section{Referencias bibliográficas}

Academia Nacional de la Historia, La Junta de Historia y Numismática Americana y el movimiento historiográfico en la Argentina (1893-1938), Buenos Aires, 1995.

Alberola, Armando (ed.), Estudios sobre Rafael Altamira, Alicante, Instituto de Estudios Juan Gil-Albert, 1988.

Altamira y Crevea, Rafael, La formación del jurista, estudio, edición y notas de Jaime del Arenal Fenochio, México, Escuela Libre de Derecho, 1993.

Calderón Quijano, José Antonio, Americanismo en Sevilla: 1900-1980, Sevilla, Escuela de Estudios Hispano-Americanos, 1987.

Devoto, Fernando J. (estudio y comp.), La historiografía argentina en el siglo XX, Buenos Aires, Centro Editor de América Latina, 1993. 
García-Gallo, Alfonso, «Problemas metodológicos de la Historia del Derecho indiano», Revista del Instituto de Historia del Derecho Ricardo Levene, 18, Buenos Aires, 1967, 13-63.

García-Gallo, Alfonso, Metodología de la Historia del Derecho Indiano, Santiago de Chile, Editorial Jurídica de Chile, 1970.

García-Gallo, Alfonso, «Antonio Muro, historiador del derecho indiano», Anuario de Estudios Americanos, XXXI, Sevilla, 1974, XXI-XXXIX.

Homenaje al Dr. Muro Orejón, Sevilla, Universidad de Sevilla, 1979, 2 vols.

Malagón, Javier, «José María Ots Capdequí, maestro de la historia institucional de América», Revista de Historia de América, 83, México, 1977, 7-17.

Malagón, Javier y Zavala, Silvio, Rafael Altamira y Crevea. El historiador y el hombre, México, UNAM, 1971.

Manzano Manzano, Juan, Historia de las Recopilaciones de Indias, 2. ${ }^{\text {a }}$ ed., Málaga, Centro de Estudios «Juan de la Rosa», 1981, 2 tomos.

Molina, Raúl A., Misiones argentinas en los archivos europeos, México, Instituto Panamericano de Geografía e Historia, Comisión de Historia, 1955.

Muro Orejón, Antonio, Lecciones de Historia del Derecho hispano indiano, México, Miguel Ángel Porrúa, 1989.

Ots Capdequí, José María, «D. Rafael Altamira y su cátedra de la Universidad de Madrid», Revista de Historia de América, 61-62, México, 1966, 217-224.

Ots Capdequí, José María, Obra dispersa, estudio preliminar de Mariano Peset, Valencia, Generalitat Valenciana, 1992.

Pasamar Alzuria, Gonzalo y Peiró Martín, Ignacio, Diccionario Akal de Historiadores españoles contemporáneos (1840-1930), Madrid, Ediciones Akal, 2002.

Pelosi, Hebe Carmen, Rafael Altamira y la Argentina, Cuadernos de América sin nombre, 11, Murcia, Universidad de Alicante, 2005.

Peña y Cámara, José María de la, Archivo General de Indias de Sevilla. Guía del visitante, Madrid, Dirección General de Archivos y Bibliotecas, 1958.

Peset, Mariano, «Un discípulo de Rafael Altamira: José María Ots Capdequí», Cuadernos del Instituto de Investigaciones Jurídicas, UNAM, 15, México, 1990, 459-474.

Prado, Gustavo H., Las lecciones historiográficas de Rafael Altamira en Argentina (1909). Apuntes sobre Ciencia, Universidad y Pedagogía Patriótica, Oviedo, Universidad de Oviedo, 2010.

Prado, Gustavo H., Las lecciones historiográficas de Rafael Altamira en Argentina (1909). Apuntes sobre Historia del Derecho, Derecho consuetudinario y modelos formativos del jurista, Pamplona, Analecta Editorial, 2015.

Rafael Altamira, 1866-1951, Alicante, Instituto de Estudios Juan Gil-Albert, 1987.

Tau Anzoátegui, Víctor, «Altamira y Levene: una amistad y un paralelismo intelectual», Cuadernos del Instituto de Investigaciones Jurídicas, UNAM, 15, México, 1990, 475-492. 
Tau Anzoátegui, Víctor, «Antonio Muro Orejón 1904-1994», Revista de Historia del Derecho, 22, Buenos Aires, 1994, 522-524.

Tau Anzoátegui, Víctor, «Diálogos sobre Derecho indiano entre Altamira y Levene en los años cuarenta», Anuario de Historia del Derecho Español, LXVII-1, Madrid, 1998, 369-389.

Tau Anzoátegui, Víctor, El futuro de la historia jurídica en las aulas, Córdoba, Asociación Argentina de Profesores e Investigadores de Historia del Derecho, 2010.

Vélez, Palmira, La historiografía americanista en España 1755-1936, Madrid, Iberoamericana, Vervuert, 2007. 